\title{
Determinación de la calidad ecológica del río Tuluá Valle del Cauca
}

\author{
César Augusto Bustamante Toro, ${ }^{1 *}$ Jhon Faber Naranjo Pardo, ${ }^{2}$ \\ José Mauricio Ahumada Gonzales²
}

\begin{abstract}
1 Universidad del Quindío, Facultad de Educación, programa Licenciatura en Biología y Educación Ambiental. Grupo de investigación BIODUQ. Cr 15 Calle 12N Armenia, Colombia. *Autor para correspondencia: ceabusta@uniquindio.edu.co

²Egresados Universidad del Quindío, Facultad de Educación, Programa Licenciatura en Biología y Educación Ambiental.
\end{abstract}

\section{Resumen}

En el período comprendido entre febrero y junio de 2011, se realizó un estudio sobre la calidad ecológica del río Tuluá en sus tramos medio y bajo en la jurisdicción del municipio de Tuluá, Valle del Cauca. Se establecieron seis puntos de muestreo donde se colectaron macroinvertebrados acuáticos y se tomaron muestras de agua para los análisis físico-químicos y bacteriológicos. Para los resultados se aplicaron los índices de contaminación acuática (ICOMO, ICOMI e ICOSUS) de Viña \& Ramírez (1998), el índice biótico de calidad del agua BMWP adaptado por Zúñiga (2004) y los índices ecológicos de diversidad alfa y beta. También se determinó la composición y estructura del ensamble de macroinvertebrados encontrándose 1174 individuos distribuidos en 3 Phyllum, 4 Clases, 12 Órdenes, 25 Familias y 12 Géneros con valores de diversidad entre medios y bajo; en términos físico-químicos y ecológicos los tramos estudiados se encuentran en condiciones que varían entre aguas limpias y de buena calidad hasta aguas muy contaminadas. Es necesario que la autoridad ambiental y la sociedad civil del municipio de Tuluá formulen y apliquen estrategias de saneamiento para la prevención y control de la contaminación de esta importante corriente hídrica que es la principal fuente de abastecimiento de dicha localidad.

Palabras clave: macroinvertebrados acuáticos, bioindicadores, calidad del agua, índices ecológicos, índices de contaminación acuática (ICA), índice biótico BMWP, río Tuluá.

Editor: Hernández-Fernández J.

Citation: Bustamante, C.A., Naranjo J.F., Ahumada J.M. (2014). Determinación de la calidad ecológica del río Tuluá Valle del Cauca. Revista Mutis 4(2).

Received: September 12, 2014; accepted: December 2, 2014; Published on line: December 31, 2014

Copyright: $\odot 2014$ Bustamante, C.A., Naranjo J.F., Ahumada J.M. This is an open-access article, which permits unrestricted use, distributions and reproduction in any medium, provided the original author and source are credited.

Competing Interests: The authors have no conflict of interest.

\section{Determining the ecological quality in the Tuluá River Valle of the Cauca}

\begin{abstract}
In the period between February and June 2011, be performed a study on the ecological quality of the Tulua river in its middle watershed and under in the jurisdiction of the municipality of Valle del Cauca Tuluá. Six points were established where were taken sampling aquatic macroinvertebrates and water samples for the physico-chemical and bacteriological analyzes. Were applied of water pollution indexes (ICOMI, ICOMO and ICOSUS) of Vina \& Ramirez (1998), biotic wa-
\end{abstract}


ter quality index BMWP adapted by Zuniga (2004) and the ecological indexes alpha and beta diversity. Was also determined the composition and structure of the macroinvertebrate assemblage where were found 1174 individuals distributed in 3 Phyllum, 4 classes, 12 orders, 25 families and 12 genus with values between middle and low of diversity; to level physicochemical and ecological the river conditions varied, were from clean waters and of good quality until polluted waters. It is necessary that the environmental authorities and civil society of the town of Tuluá formulate and implement sanitation strategies for prevention and control of pollution of this important water stream is the main source of supply of the town.

Keywords: Macroinvertebrates, Bioindicators, Water quality, Ecological index, Aquatic Pollution Index, BMWP Biotic Index, Tuluá River.

\section{Introducción}

Los ecosistemas fluviales de la zona andina colombiana son altamente complejos y diversos debido a la morfología del paisaje, a la geología, a los microclimas, y a las lluvias; y son de elevada importancia económica, sociocultural y bioecológica para todo el territorio nacional (Nieto, 2010). Desde esta perspectiva surge la necesidad de estudiar dichos ecosistemas abordando los atributos ecológicos o para identificar la potencialidad ambiental de cada uno de ellos, con lo cual se podrán definir con claridad y sustento los diferentes usos que los asentamientos humanos pueden usufructuar.

Uno de los métodos para estudiar las condiciones ecológicas de los ríos se basa principalmente en la valoración de la calidad del agua que evalúa la naturaleza física, química y biológica de esta en relación con sus posibles usos (Prat 1998, tomado de Milán 2011), el empleo de dichas variables tiene como ventajas: los cambios detallados, la determinación precisa de los contaminantes y la fácil estandarización, pero presentan el problema de ser testigos de solo condiciones puntuales (Álvarez, 2005); por esta razón en los últimos años, muchos países han adoptado como complemento la inclusión de algunas comunidades acuáticas como bioindicadores ya que son parte fundamental en la evaluación integral de la calidad ecológica de los ecosistemas acuáticos (Fernández et al., 2003 y Roldán 2003).
La mayor parte de los investigadores consideran a los macroinvertebrados acuáticos como los mejores indicadores ecológicos de la calidad del agua debido a los siguientes atributos (Zúñiga y Cardona, 2009): sus largos ciclos de vida y movilidad restringida, abundancia y distribución cosmopolita, así como su especificidad con respecto al hábitat y su capacidad de expresar condiciones que han prevalecido a largo plazo.

Algunas de las mediadas utilizadas con base a los macroinvertebrados están el índice biótico BMWP (Biological Monitoring Working Party), muy popular y de uso frecuente en evaluaciones ambientales de calidad de agua. En varias regiones del país como Antioquia, Cauca, La sabana de Bogotá y Norte de Santander, hay adaptaciones del índice realizadas con base en la fauna de macroinvertebrados que tipifica las zonas (Roldan, 2003; Riss et al., 2002; Lievano \& Ospina, 2007) citado por Zúñiga y Cardona (2009).

En consideración a esta premisa, la determinación de diferentes índices tales como el índice de contaminación acuática (ICA), el BMWP y los índices ecológicos de diversidad, permiten determinar de manera complementaria, las condiciones de calidad ecológica de una fuente hídrica y servir de base en la toma de decisiones con respecto a la oferta y demanda hídrica (Bustamante et al., 2008-a y b).

Por lo anterior, en este proyecto se evaluó la calidad ecológica del agua del río Tuluá a partir del análisis de variables físico-químicas, bacteriológicas, macroinvertebrados, índice BMWP y los ICA, con el fin de contribuir a la actualización de la línea base para la gestión integral de esta corriente que es la principal fuente de abastecimiento del municipio de Tuluá, Valle del Cauca.

\section{Materiales y Métodos}

\section{Zona de estudio}

La cuenca del río Tuluá (figura 1), se encuentra ubicada en el departamento del Valle del Cauca, al occidente de la Cordillera Central. Nace a una altura de 4.100 msnm, en el Páramo de Las Hermosas el cual hace parte del Sistema de Parques Nacionales Naturales (PNN); desciende en un trayecto de $72 \mathrm{~km}$ hasta desembocar en el río Cauca a $900 \mathrm{msnm}$, el río cuenta con un caudal promedio de 15.7 ( $\left.\mathrm{m}^{3} / \mathrm{s}\right)$. Los principales ríos que fluyen hacia el río Tuluá son: Cofre, Loro, 
San Antonio, San Marcos y Nogales (CVC y UNIVALLE 2006, Tomado de Arias 2007).

El área de estudio comprende tramos localizados en los segmentos medio y bajo del río, desde la cascada La Arenosa ubicada en el corregimiento de Mateguadua, hasta el kilómetro uno aguas arriba de la planta de tratamiento de aguas residuales (PTAR) del municipio de Tuluá.

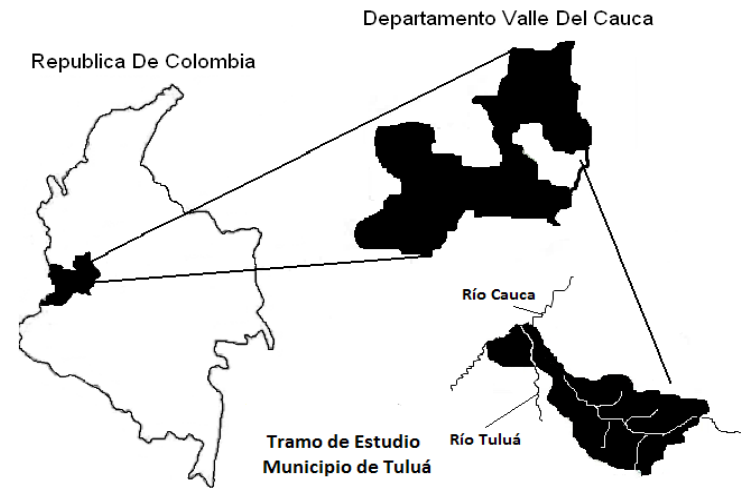

Figura 1. Localización área de estudio del río Tuluá, departamento del Valle del Cauca

\section{Fase de campo}

Los muestreos se realizaron mensualmente entre febrero y junio de 2011, para ello se establecieron tres estaciones de muestreo en cada tramo del río (tabla 1) basados en el gradiente altitudinal y longitudinal. El tramo medio se caracteriza por presentar vegetación ribereña, cauce con variedad de sustratos naturales (material rocoso y vegetal) y poca intervención antrópica; por su parte, el tramo bajo se caracteriza por ser una zona intervenida antropicamente donde hay explotación de material de arrastre, se aprecia escasa vegetación ribereña, el cauce con presencia de arenas y gravas como sustrato predominante, hay vertimientos puntuales de aguas residuales domésticas y sitios donde el río esta canalizado. A nivel general la zona ribereña del río Tuluá se caracteriza por presentar una cobertura vegetal, principalmente de familias de Melastomataceas, Araceas, Bromeliaceas, Mirtaceas y especialmente Poaceas.

Tabla 1. Estaciones de muestreo parte media y baja del río Tuluá

\begin{tabular}{|c|c|c|c|}
\hline ESTACIÓN & Tramo & COORDENADAS & Elevación msnm \\
\hline E1 Cascada La Arenosa & Media & $4^{\circ} 00^{\prime} 05.16^{\prime \prime} \mathrm{N}$ y $76^{\circ} 09^{\prime} 14.56^{\prime \prime} \mathrm{O}$ & 1202 \\
\hline E2 Jardín Botánico & Media & $4^{\circ} 01^{\prime} 40.06^{\prime \prime} \mathrm{N}$ y $76^{\circ} 10^{\prime} 10.06^{\prime \prime} \mathrm{O}$ & 1094 \\
\hline E3 Barrio Nueva Fátima & Media & $4^{\circ} 04^{`} 12.51^{\prime \prime} \mathrm{N}$ y $76^{\circ} 11^{\prime} 42.07^{\prime \prime} \mathrm{O}$ & 996 \\
\hline E4 Villa Nueva & Baja & $4^{\circ} 05^{`} 10.52^{\prime \prime} \mathrm{N}$ y $76^{\circ} 11^{\prime} 41.14^{\prime \prime} \mathrm{O}$ & 978 \\
\hline E5 Portales del Río & Baja & $4^{\circ} 06^{\prime} 09.08^{\prime \prime} \mathrm{N}$ y $76^{\circ} 11^{\prime} 49.30^{\prime \prime} \mathrm{O}$ & 962 \\
\hline E6 $1 \mathrm{~km}$ aguas arriba de PTAR & Baja & $4^{\circ} 07^{`} 02.07^{\prime \prime} \mathrm{N}$ y $76^{\circ} 12^{`} 25.05^{\prime \prime} \mathrm{O}$ & 950 \\
\hline
\end{tabular}

\section{Variables físico-químicas y bacteriológicas}

En cada estación de muestreo, se midieron in situ: $\mathrm{pH}$, temperatura del agua, conductividad, oxígeno disuelto y porcentaje de saturación de oxígeno. Adicionalmente se tomaron muestras de agua para ser trasladas al Laboratorio de Aguas y Ambiental de la Universidad del Quindío, donde se hicieron los análisis de las variables: demanda bioquímica de oxígeno (DBO), solidos suspendidos, alcalinidad, dureza total, coliformes fecales y totales, siguiendo los protocolos recomendados por el estándar de métodos de la APHA AWWA (2005).

\section{Comunidad de macroinvertebrados}

La comunidad de macroinvertebrados acuáticos se colectó mediante el empleo de una red Surber de 30. $5 \times 30.5 \times 8 \mathrm{~cm}$, obteniendo material en las márgenes y centro de la corriente, con un esfuerzo de una hora de muestreo con réplicas. También se capturaron los macroinvertebrados adheridos a rocas y hojarasca empleando pinzas entomológicas.

Las muestras se fijaron en alcohol al $70 \%$ y glicerina en recipientes previamente etiquetados para así ser trasladados al Laboratorio de Biología de la Universidad del Quindío para su correspondiente identificación hasta el nivel de familia y en algunos casos donde fue posible hasta género, con base en las descripciones y claves de: Pennak (1978), Merritt \& Cummins (1996), Roldán (1996), Vargas (1997), Posada \& Roldán (2003), Roldán (2003), Camacho \& Molano (2005), Álvarez (2005) y Domínguez \& Fernández (2009).

\section{Análisis y tratamiento de la información}

Para describir la estructura de la comunidad de macroinvertebrados en cada estación de muestreo, se 
aplicaron los índices de diversidad alfa, Shannon-Wiener $\left(H^{\prime}\right)$, Dominancia de Simpson $\left(D^{\prime}\right)$ y Equidad de Pielou (J'); para la diversidad beta se realizó un análisis de agrupamiento de ausencia-presencia con el índice de similitud de Jaccard para comparar la composición de macroinvertebrados entre las estaciones de muestreo. Todos los análisis se realizaron con el programa PAST V 2.15

Se empleó el programa ICATEST V 1.0 (Fernández et al., 2003) para cuantificar el grado de contaminación de las aguas por medio de los índices propuestos por Viña y Ramírez (1998): ICOMI índice de contaminación por minerales que incluye las variables (conductividad, dureza total y alcalinidad); ICOSUS índice de contaminación por sólidos suspendidos que incorpora la variable (sólidos suspendidos) y el ICOMO índice de contaminación por materia orgánica que involucra las variables (DBO, coliformes fecales y porcentaje de saturación de oxígeno). Para el análisis biológico se aplicó el índice biótico BMWP modificado y adaptado por Zúñiga (2004).

\section{Resultados y Discusión}

\section{Composición y estructura de macroinvertebrados acuáticos}

La comunidad de macroinvertebrados a lo largo del segmento muestreado está representada por 1.174 individuos, pertenecientes a 3 phyla, 4 clases, 12 órdenes, 25 familias y 12 géneros (tabla 2). Se puede decir al respecto, que la distribución de la riqueza de taxa y de la abundancia de dicha comunidad disminuye en función del descenso altitudinal, la heterogeneidad del cauce y la calidad físico-química y bacteriológica del agua de los tramos estudiados. Situación que responde a los cambios generados principalmente por las actividades antrópicas que influyen notoriamente en las alteraciones del paisaje y de la geomorfología del cauce; estas últimas son fundamentales para la presencia de biotopos y el ensamble de comunidades bióticas, como lo expresan Milán et al. (2011) y Arias (2007).

Tabla 2. Listado taxonómico de la comunidad de macroinvertebrados acuáticos de la parte media y baja del río Tuluá

\begin{tabular}{|c|c|c|c|c|}
\hline PHYLLUM & CLASE & ORDEN & FAMILIA & GENERO \\
\hline \multirow[t]{23}{*}{ Artrópoda } & Insecta & Trichóptera & Hydrobiosidae & Atopsyche \\
\hline & & & Helicopsychidae & Helicopsyche \\
\hline & & & Leptoceridae & \\
\hline & & & Glossosomatidae & \\
\hline & & & Hydropsychidae & Smicridea \\
\hline & & & Calamoceratidae & Phylloicus \\
\hline & & & Philopotamidae & \\
\hline & & Plecóptera & Perlidae & Anacroneuria \\
\hline & & Ephemeróptera & Oligoneuriidae & \\
\hline & & & Leptophlebiidae & Farrodes \\
\hline & & & Baetidae & Andesiops \\
\hline & & & & Baetodes \\
\hline & & Coleóptera & Psephenidae & Psephenops \\
\hline & & & Ptilodactylidae & \\
\hline & & & Elmidae & \\
\hline & & & Hydrophilidae & \\
\hline & & Megalóptera & Corydalidae & Corydalus \\
\hline & & Hemíptera & Gerridae & \\
\hline & & & Veliidae & \\
\hline & & Díptera & Chironomidae & Chironomus \\
\hline & & & Blephariceridae & \\
\hline & & Odonata & Libellulidae & \\
\hline & & Lepidóptera & Pyralidae & \\
\hline \multirow[t]{2}{*}{ Annélida } & Hirudinea & Rhynchobdellida & Glossiphoniidae & \\
\hline & Oligochaeta & Haplotaxida & Tubificidae & Tubifex \\
\hline Mollusca & Gastrópoda & Basommatóphora & Physidae & \\
\hline
\end{tabular}


La clase más representativa fue Insecta con 9 órdenes y 23 familias, el orden más diverso fue Trichóptera con 7 familias y 5 géneros, alcanzando una representatividad del $25 \%$ de los taxones; situación que obedece a que los insectos son el grupo más diverso de los ecosistemas acuáticos y terrestres, ocupan gran variedad de hábitats y nichos funcionales a lo largo de un amplio espectro de escalas espaciales y temporales (Roldan \& Ramírez, 2008). Las clases menos representativas fueron Hirudinea, Oligochaeta y Gastropoda cada uno representada por un orden y una familia, este grupo de organismos se relaciona con taxas que son considerados muy resistentes a las condiciones ambientales adversas en los sistemas lóticos.

Tabla 3. Número de familias, individuos y abundancia relativa por estación de muestreo

\begin{tabular}{cccc}
\hline ESTACIÓN & FAMILIAS & $\begin{array}{c}\text { TOTAL } \\
\text { INDIVIDUOS }\end{array}$ & $\begin{array}{c}\text { ABUNDANCIA } \\
\text { RELATIVA (\%) }\end{array}$ \\
\hline E1 & 14 & 773 & 65.8 \\
E2 & 13 & 158 & 13.4 \\
E3 & 6 & 69 & 5.9 \\
E4 & 4 & 66 & 5.6 \\
E5 & 2 & 56 & 4.7 \\
E6 & 6 & 52 & 4.4 \\
\hline
\end{tabular}

La estación E1 fue la que presentó la mayor riqueza y abundancia con 14 familias representadas por 773 individuos equivalente al $65.8 \%$, favorecida por presencia de aguas limpias y un cauce con presencia de material alóctono proveniente de las riberas y con sustratos rocosos que favorece el ensamble de la biota acuática (tabla 3); por su parte la estación E5 presentó la menor riqueza y abundancia con tan solo 2 familias y 56 individuos equivalentes al $4.7 \%$, lo que demuestran las afectaciones de hábitat fluvial y la contaminación de las aguas en la parte baja del río Tuluá, limitan la oferta de nichos ecológicos y por ende condiciona una escasa diversidad de macroinvertebrados bentónicos.

En consideración con algunos autores como Álvarez (2005), Roldán y Ramírez (2008) y Zúñiga y Cardona (2009), se puede inferir que en sitios donde se evidencie una afectación del cauce y una reducción y fragmentación de la cobertura vegetal de la zona ribereña por actividades antrópicas como la minería, la ganadería y la agricultura, se presenta una reducción en la diversidad, como se aprecia en las estaciones E4 y E5.

De acuerdo a Blinn \& Kilgore, (2001) citado por González et al. (2012), el bosque ribereño cumple un pa- pel fundamental al retardar y reducir la escorrentía superficial, utilizar el exceso de nutrientes, atrapar los sedimentos y otros contaminantes que se desprenden de los suelos descubiertos o suelos de cultivo y de esta manera proteger los cuerpos de agua; dicho aspecto favorece la composición de macroinvertebrados bentónicos, como se aprecia en las estaciones E1 y E2 asociados al tramo medio del río Tuluá.

Tabla 4. Diversidad y estructura de los macroinvertebrados

\begin{tabular}{|c|c|c|c|}
\hline ESTACIÓN & $\begin{array}{l}\text { Shannon - } \\
\text { Winer }\left(\mathbf{H}^{\prime}\right)\end{array}$ & Simpson (D') & Pielou ( $\left.\mathbf{P}^{\prime}\right)$ \\
\hline E1 & 2.6 & 0.08 & 0.96 \\
\hline E2 & 2.1 & 0.17 & 0.81 \\
\hline E3 & 1.6 & 0.23 & 0.81 \\
\hline E4 & 1.2 & 0.33 & 0.88 \\
\hline E5 & 0.1 & 0.93 & 0.22 \\
\hline E6 & 1.6 & 0.21 & 0.90 \\
\hline
\end{tabular}

Las estaciones 1, 2, 3, 4 y 6 presentaron valores cercanos a cero en dominancia ( $\left.D^{\prime}\right)$ y valores de equidad mayores $\left(\mathrm{P}^{\prime}: 0.80\right)$, lo cual se traduce en que poseen distribuciones mucho más homogéneas y que habitan en tramos con mejores condiciones ecológicas con respecto a la estación E5 que presentó el valor más bajo en diversidad $\left(H^{\prime}: 0.1\right)$, el valor más alto en dominancia ( $D$ : 0.93 ) y por ende una baja equidad $\left(P^{\prime}: 0.22\right)$. Esta situación se debe a la dominancia de las taxa Tubificidae y Chironomidae en dicho trayecto, pues de acuerdo a Roldán (2003), estas taxa reflejan ambientes perturbados ecológicamente con presencia de materia orgánica en descomposición y aguas contaminadas.

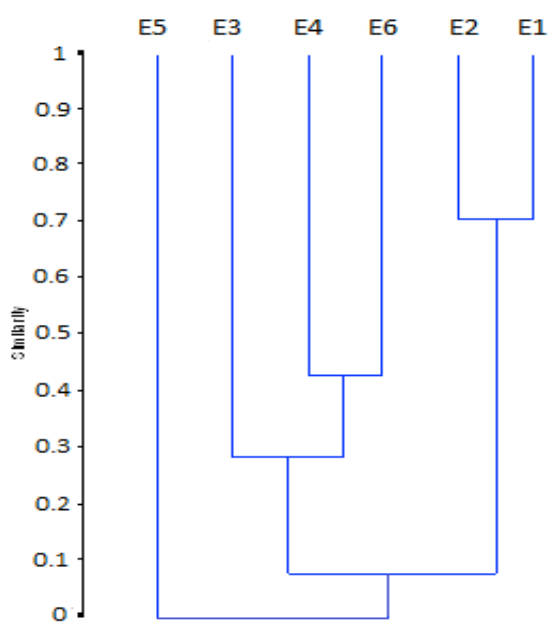

Figura 2. Dendograma de similitud entre familias de macroinvertebrados en las estaciones de muestreo (E) del río Tuluá 
El dendograma de similitud Jaccard (Figura 2), muestra que la mayor similaridad se presentó entre las estaciones E1 y E2, con (71\%) de homogeneidad en cuanto a los grupos taxonómicos registrados, seguidos por las estaciones E4 y E6 con (43\%) de similaridad; lo anterior puede deberse al parentesco de estas locaciones en sustratos, a la geomorfología del cauce, al paisaje ribereño y a las condiciones físico-químicas y ecológicas reportadas en dichas estaciones.

La estación E5 no registró similitud $(0 \%)$ con respecto a las otras estaciones, ya que la composición de las familias de macroinvertebrados fue diferente, pues en dicha estación E5 solo se encontraron unos pocos organismos que son resistentes o tolerantes a las condiciones de contaminación acuática.

\section{Índice biótico}

El análisis de los resultados del índice BMWP (tabla 5), fueron registrados para cada estación de muestreo de la siguiente manera:

Tabla 5. Valores del índice biótico BMWP (Zúñiga, 2004) en cada estación de muestreo

\begin{tabular}{ccl}
\hline ESTACIÓN & PUNTAJE & CATEGORÍA \\
\hline E1 & 127 & Muy limpia \\
E2 & 109 & No contaminada \\
E3 & 37 & Contaminación \\
E4 & 13 & Muy contaminada \\
E5 & 3 & Séptica \\
E6 & 21 & Muy contaminada \\
\hline
\end{tabular}

Estación E1 (cascada La Arenosa)

La E1 se caracteriza por poseer una gran vegetación ribereña medianamente intervenida, la cual ofrece una mayor cantidad y variedad de hábitats para el desarrollo de macroinvertebrados acuáticos en el cauce, lo cual probablemente haya favorecido la riqueza y abundancia de organismos en comparación con las demás estaciones evaluadas.

En esta estación el valor del índice BMWP fue de 127 puntos, lo que significa aguas muy limpias de calidad buena (tabla 5); situación que se debe a la riqueza y dominancia de organismos como los Trichopteros representados por las familias Calamoceratidae, Helicopsychidae, Leptoceridae e Hydrobiosidae; los Ephemeropteros representados por las familias Oligoneuriidae y Leptophlebiidae; y los Plecopteros representados por la familia Perlidae. Todos estos organismos son asociados a indicadores de aguas de muy buena calidad.

\section{Estación E2 (Jardín Botánico)}

La estación E2 presenta biológica y biogeofísicamente condiciones muy similares a la estación E1 pero la abundancia fue menor. El valor del índice BMWP fue de 109 puntos, lo que indica que el agua es muy limpia y de buena calidad.

\section{Estación E3 (barrio Nueva Fátima)}

El valor del índice BMWP registró 37 puntos, indicando aguas moderadamente contaminadas y de dudosa calidad; en este tramo disminuye drásticamente la vegetación de ribera y se presenta intervención constante por la extracción artesanal de materiales del lecho (arena y grava) por parte de algunos habitantes del municipio.

En esta estación se aprecia una disminución de la riqueza de los macroinvertebrados acuáticos, solamente hay presencia de organismos que toleran ambientes alterados con cierto grado de contaminación, por ende predominaron organismos del orden coleóptera representados por las familias Elmidae, Hydrophilidae y Scyrtidae; el orden Ephemeroptera registró la familia Baetidae.

\section{Estación E4 (Villa Nueva)}

Esta estación no presenta vegetación ribereña asociada al cauce debido a que este tramo del río se encuentra canalizado, que de algún manera, afecta la dinámica, composición y estructura de las comunidades acuáticas; en tal sentido, se encontraron organismos que toleran medios y altos grados de degradación y contaminación acuática como los son las familias: Glossiphoniidae, Physidae, Hydrophilidae y Elmidae.

El puntaje obtenido del BMWP fue de 13, por tanto nos indica que el agua de esta estación se encuentra muy contaminada y de calidad crítica, lo que también coincide con los valores obtenidos de los ICA.

\section{Estación E5 (Portales del Río)}

Este tramo del río Tuluá registró el valor más bajo del índice BMWP, siendo de 3 puntos, lo que significa aguas fuertemente contaminadas (séptica) y de calidad muy crítica, por consiguiente esta estación registró la menor diversidad y solo hay dominancia de las taxa Chironomidae y Tubificidae. Según Roldán y Ramírez (2008), estos organismos habitan y toleran 
aguas con presencia de materia orgánica en descomposición y contaminadas.

Real \& Prat (1992) afirman que la densidad de estos individuos aumenta cuando hay bajos niveles de oxígeno como los encontrados en el presente estudio para esta estación, estos concuerdan con lo propuesto por Toro et al. (2003) indicando que los oligoquetos (Tubificidae) se encuentran asociados a otras características como aguas turbias y con presencia de contaminación por materia orgánica.

\section{Estación E6 (1 $\mathrm{km}$ aguas arriba PTAR)}

Para esta estación el valor del índice BMWP fue de 21 puntos, lo cual se relaciona a aguas muy contamina- das y de calidad crítica. Este tramo del río Tuluá registró familias que toleran niveles medios de contaminación como Glossiphoniidae, Hydrophilidae, Guerridae y Veliidae, pero también se encontraron algunas familias que no son tan tolerantes como Elmidae y Libellulidae.

En términos generales, con base a lo planteado por Zúñiga (2004), se puede decir que a lo largo de los tramos estudiados se evidencian cambios significativos en cuanto a la diversidad, distribución y abundancia de los macroinvertebrados, posiblemente asociados al deterioro del cauce, de los hábitats y de la calidad del agua.

\section{Índices de contaminación acuática}

Tabla 6. Valores de los índices de contaminación acuática: ICOMI, ICOMO, ICOSUS propuestos por Ramírez y Viña (1998)

\begin{tabular}{ccccccc}
\hline ESTACIÓN & ICOMI & INDICADOR DE CALIDAD & ICOMO & INDICADOR DE CALIDAD & ICOSUS & INDICADOR DE CALIDAD \\
\hline E1 & 0,09 & Muy buena & 0,13 & Muy buena & 0,29 & Buena \\
E2 & 0,21 & Buena & 0,17 & Muy buena & 0,34 & Buena \\
E3 & 0,2 & Buena & 0,26 & Buena & 0,57 & Media \\
E4 & 0,43 & Media & 0,29 & Buena & 0,64 & Mala \\
E5 & 0,52 & Media & 0,53 & Media & 0,82 & Pésima \\
E6 & 0,22 & Buena & 0,48 & Media & 0,45 & Media \\
\hline
\end{tabular}

Los resultados de las variables físico-químicas y bacteriológicas analizadas durante el período de estudio mostraron a nivel general que la conductividad, alcalinidad, dureza total, $\mathrm{pH}$, oxígeno disuelto, el porcentaje de saturación de oxígeno y la DBO, presentaron pocas variaciones (anexo 1). Sin embargo, las variables solidos suspendidos y coliformes, fueron las que más variación presentaron.

El pH presentó valores cercanos a la neutralidad, lo cual indica cierta estabilidad química del agua en los trayectos del río estudiados. La alcalinidad reporto valores de entre 18 y 105 mg/l CaCO3, según los estándares nacionales en calidad del agua el valor máximo de alcalinidad no sobrepasa el valor máximo permisible (200 $\mathrm{mg} / \mathrm{CaCO} 3)$, por tanto las aguas del río Tuluá pueden mantener y regular procesos ecológicos y de productividad. Con respecto a los valores de oxígeno disuelto, presentó valores más altos $7.8 \mathrm{mg} / \mathrm{l}$ en las estaciones E1 y E2 asociadas a la parte media, a diferencia de la estación $\mathrm{E} 5$ de la parte baja del río Tuluá que presentó el valor más bajo de oxigeno disuelto, $4.5 \mathrm{mg} / \mathrm{l}$ y el valor más alto de DBO $9.2 \mathrm{mg} / \mathrm{l}$, resultados que coinciden con los registros de baja diversidad de macroinvertebrados pero de alta dominancia de unos pocos taxas que son considerados resistentes o tolerantes a condiciones de aguas con degradación de materia orgánica, como se evidencia en este tramo del río.

Los resultados de los ICA para el río Tuluá permiten inferir que las estaciones E1 y E2 de la parte media no presentan ningún tipo de contaminación acuática; sin embargo, los resultados de los índices ICOMI e ICOMO reportan que las estaciones E4 y E5 de la parte baja presentaron contaminación media, indicando algún grado de alteración del agua por minerales y materia orgánica; entre tanto el índice ICOSUS reporto valores entre medios y altos en las estaciones E3, E4 y E5; indicando contaminación por sólidos suspendidos.

Con respecto a la variabilidad de los índices de diversidad, BMWP y los ICA, coinciden y evidencian que el río Tuluá en su trayecto medio presenta condiciones de buena calidad de sus aguas, mayor diversidad y abundancia de macroinvertebrados y de hábitats fluviales, mientras que en su trayecto bajo corresponde a condiciones de deterioro de sus aguas, de baja diversidad y alta dominancia de unas pocas taxas y de alteraciones paisajísticas y geomorfológicas del cauce. 
Es de tener en cuenta que los coliformes fecales de las estaciones E5 y E6 registraron valores superiores a los 5000 UFC/100ml (anexo 1), según el decreto 1594 de 1984, estos valores exceden los límites permisibles para varios usos. Esta situación puede deberse al vertimiento de las aguas residuales municipales y a las alteraciones del paisaje y del cauce de la parte baja del río Tuluá

El índice ICOSUS reportó valores entre medios y altos en las estaciones E3, E4 y E5; indicando contaminación por sólidos suspendidos. Los sólidos aumentaron sobre todo en época de lluvias, el valor máximo para sólidos suspendidos fue de $388 \mathrm{mg} / \mathrm{l}$, y para los sólidos totales fue de $419 \mathrm{mg} / \mathrm{l}$; dicha situación se debe al arrastre de sedimentos y a la desprotección de las riberas del cauce.

De acuerdo a los resultados de los ICA, los tramos de la parte baja del río Tuluá presentan deterioro en la calidad de sus aguas, quizás debido a las captaciones del agua para uso doméstico, industrial y agrícola que disminuyen el caudal, a la extracción severa de material de arrastre, a la transformación paisajística de la zona ribereña, a la canalización de un trayecto importante y del vertimiento de aguas residuales domesticas e industriales. Pero también, se nota una leve recuperación del río Tuluá en la estación E6, dado que descienden los valores de los ICA.

\section{Conclusiones}

Los resultados del índice BMWP reportan que las condiciones de calidad del ambiente acuático del río Tuluá van desde aguas muy limpias y de buena calidad en la parte media, hasta aguas muy contaminadas y de calidad muy crítica en la parte baja.

Los resultados de la mayoría de las variables físico-químicas, la composición, estructura y distribución de la comunidad de macroinvertebrados y los valores arrojados por los índices BMWP y los ICA, infieren en que las estaciones E1 y E2 presentaron las mejores condiciones de calidad ecológica del agua y las estaciones E4 y E5 presentaron deterioro en la calidad de sus aguas. Este último como consecuencia de las transformaciones del cauce, paisaje y del vertimiento directo de aguas residuales domésticas.

La degradación de la calidad del agua del tramo bajo del río Tuluá, sugiere que se formule y aplique un plan de ordenamiento ambiental y acciones en saneamiento y manejo de vertimientos que sea participati- vo e incluyente, teniendo en cuenta atributos ecológicos y los bienes y servicios que este ofrece y las alteraciones y conflictos socioculturales que se presentan en este zona.

\section{Referencias}

Alba Tercedor, J. (1996). Macroinvertebrados acuáticos y calidad de las aguas de los ríos. IV Simposio del agua en Andalucía (SIAGA). Almería. Vol. II.

Apha-Awwa-Apcf. (2005). Métodos normalizados para el análisis de aguas potables y residuales. (Ed.) Díaz de Santos, Madrid.

Álvarez Arango, L. F. (2005). Metodología para la evaluación de los macroinvertebrados acuáticos como indicadores de los recursos hidrobiológicos. Instituto Alexander Von Humboldt. Medellín, Colombia. 139.

Arias, F. (2007). Evaluación del desarrollo sostenible de la cuenca del rio Tuluá: a propósito de los planes de ordenamiento y manejo de cuencas hidrográficas. Universidad del Valle.

Bustamante, C. A.; Torres, S. L.; Dávila, C.A. \& Ortiz, J. F. (2008-a). Estudio preliminar de la Composición y abundancia del fitoperifiton en el río Quindío. Revista de Investigaciones Universidad del Quindío. 18: 15-21.

Bustamante, C. A.; Monsalve, E. A.; \& García, P. L. (2008-b). Análisis de la calidad de agua en la cuenca media del río Quindío con base en índices físicos, químicos y biológicos. Revista de Investigaciones de la Universidad del Quindío. 18: 22-31.

Camacho Pinzón, D; Molano Rendón, F. (2005). Clave ilustrada de especies para Gerridae (Insecta: Heteroptera) del departamento del Quindío-Colombia. Revista de Investigaciones de la Universidad del Quindío.15:75-82.

Domínguez, E., \& Fernández, H. (2009). Macroinvertebrados bentónicos sudamericanos. Sistemática y biología. Primera Edición. Universidad Nacional de Tucumán. Facultad de Ciencias Naturales. Instituto M. Lillo. Tucumán, Argentina. 282.

Fernández, N.; Ramos, G.; \& Solano, F. (2003). ICATEST $\checkmark$ 1.0. Una herramienta informática para el análisis 
y valoración de la calidad del agua. Universidad de Pamplona. Vol. 2

González, S. M., Ramírez, Y. P., Meza, A. M. y Días, L. G. (2012). Diversidad de macroinvertebrados acuáticos y calidad del agua de quebradas abastecedoras del municipio de Manizales. Boletín Científico Centro de Museo de Historia Natural. 16 (2): 135 $-148$.

Milán, W.; Caicedo, O.; Aguirre, N. (2011). Quebrada La Popala: un análisis de calidad del agua. Desde algunas variables físico-químicas, microbiológicas y los macroinvertebrados acuáticos. Revista gestión y ambiente. 85-94.

Ministerio de Salud. República de Colombia. Decreto 1594 de 1984 capítulos 3, 4 y 5.

Merritt, R. W., \& Cummins, K. W. (1996). An Introduction to the Aquatic Insects of North America. Third edition. Kendall/Hunt Publishing Company. Iowa. $862 \mathrm{pp}$.

Nieto, O. (2010). Armenia Colombia: Gestión Integral de las Microcuencas y de las Áreas Naturales Protegidas, Armenia, Quindío.

Pennak, R. (1998). Freshwater invertebrates of United States. Third edition. Wiley-Interscience, New York. 628 pp.

Posada García, J. \& Roldán Pérez G. (2003). Clave ilustrada de las larvas de Trichoptera en el nor-occidente de Colombia. Caldasia 25(1): 169-192.

Ramírez, J., \& Viña, V. (1998). Limnología Colombiana. Aportes a su conocimiento y estadísticas de análisis. Universidad Jorge Tadeo Lozano. Bogotá Distrito Capital. Primera edición - BP exploration company (Colombia) Ltda.

Real M. \& Prat N. (1992). Factors influencing the distribution of chironomids and oligochates in profundal areas of spanish reservoirs. Netherlands Journal of Aquatic Ecology. 26(2):405-410.

Roldán, G. \& Ramírez, J. J. (2008). Fundamentos de Limnología Neotropical. Editorial Universidad de Antioquia, Segunda Edición. Medellín-Colombia. pp. $180-238$

Roldán, G. (2003). Bioindicación de la calidad del agua en Colombia. Propuesta para el uso del método BMWP/Col. Ciencia y Tecnología. Universidad de Antioquia. Medellín. $170 \mathrm{p}$.

Roldán, G. (1996). Guía para el estudio de los macroinvertebrados acuáticos del departamento de Antioquia. FEN-Colciencias, Bogotá, 217 p.

Toro, J. L.; Londoño, O. A.; Arrubla, J. P.; Zárate, M. P.; Torres, M. D.; Beltrán, I. M.; (2003). Determinación de la calidad ambiental del río Santo Domingo, municipio de Calarcá. Rev. Col. Investigaciones Universidad del Quindío No. (14): 39-48.

Vargas, I. C. (1997). Inventario preliminar de los macroinvertebrados bentónicos en el río Quindío y la quebrada Cristales. C.R.Q. Armenia, Quindío.

Zúñiga, M. C. (2004). Evaluación hidrobiológica (macroinvertebrados bentónicos, fitoplancton y zooplancton) y de calidad del agua a lo largo de nueve estaciones de muestreo del río Cauca. Corporación Autónoma del Valle del Cauca, CVC. Universidad del Valle. Vol. XII.

Zúñiga M. C. \& Cardona W. (2009). Bioindicadores de calidad del agua y caudal ambiental. En: capítulo 7. Caudal Ambiental: Conceptos, Experiencias y Desafíos. Programa editorial Universidad del Valle. Pag 167-198.

\section{Anexo 1}

Estadísticas descriptivas, variables físico-químicas y bacteriológicas de la calidad del agua del río Tuluá

\begin{tabular}{|c|c|c|c|c|}
\hline Variables & mínimo & máximo & media & C.V \\
\hline $\begin{array}{l}\text { Temperatura del agua } \\
\left({ }^{\circ} \mathrm{C}\right)\end{array}$ & 16.1 & 22.2 & 19.5 & 11 \\
\hline $\mathrm{pH}$ & 4.8 & 7.4 & 6.5 & 14.7 \\
\hline Oxígeno disuelto (mg/l) & 4.5 & 7.8 & 6.0 & 19.9 \\
\hline \% saturación de oxígeno & 58 & 88 & 67 & 32 \\
\hline Conductividad (us/cm) & 27 & 192 & 85 & 44.5 \\
\hline $\begin{array}{l}\text { Dureza total }(\mathrm{mg} / \mathrm{l} \\
\mathrm{CaCO} 3)\end{array}$ & 34 & 95 & 55 & 25 \\
\hline Alcalinidad (mg/l CaCO3) & 36 & 105 & 77 & 39 \\
\hline $\mathrm{DBO}_{5}(\mathrm{mg} / \mathrm{l})$ & 3,3 & 9.2 & 7.7 & 23 \\
\hline Solidos disueltos (mg/l) & 65 & 389 & 156 & 55.5 \\
\hline $\begin{array}{l}\text { Coliformes fecales } \\
\text { (NMP/100 ml) }\end{array}$ & 100 & 5000 & 2350 & 250 \\
\hline $\begin{array}{l}\text { Coliformes totales (NMP } \\
100 \mathrm{ml} \text { ). }\end{array}$ & 250 & 5600 & 2500 & 267 \\
\hline
\end{tabular}

